\title{
Natural Bond Orbital (NBO) Population Analysis of 1-Azanapthalene-8-ol
}

\author{
Rubarani P. GANGADHARAN ${ }^{a}$ AND S. SAMPATH KRISHNAN ${ }^{b, *}$ \\ ${ }^{a}$ Department of Physics, Rajalakshmi Engineering College, Chennai 602105, India \\ ${ }^{b}$ Department of Applied Physics, Sri Venkateswara College of Engineering, Chennai 602105, India
}

(Received July 2, 2013; in final form November 22, 2013)

\begin{abstract}
The molecular structure of 1-azanapthalene-8-ol was calculated by the B3LYP density functional model with 6-31G $(\mathrm{d}, \mathrm{p})$ basis set by Gaussian program. The results from natural bond orbital analysis have been analyzed in terms of the hybridization of atoms and the electronic structure of the title molecule. The stability of the molecule arising from hyper conjugative interactions, charge delocalization has been analyzed using natural bond orbital analysis. The electron density based local reactivity descriptors such as the Fukui functions were calculated. The dipole moment $(\mu)$ and polarizability $(\alpha)$, anisotropy polarizability $(\Delta \alpha)$ and first order hyperpolarizability $\left(\beta_{\text {tot }}\right)$ of the molecule have been reported.
\end{abstract}

DOI: $10.12693 /$ APhysPolA.125.18

PACS: $33.20 . \mathrm{Tp}, 31.15 . \mathrm{Ae}, 31.15 . \mathrm{Ar}, 31.15 . \mathrm{Ew}$

\section{Introduction}

1-azanapthalene-8-ol also called as 8-hydroxy quinoline is an organic compound with the formula $\mathrm{C}_{9} \mathrm{H}_{7} \mathrm{NO}$ and the geometric structure of 1-azanaphthalene-8-ol is shown in Fig. 1. It is a derivative of the heterocyclic quinoline by placement of an $\mathrm{OH}$ group on carbon number 8 . This light yellow compound is widely used commercially, although under a variety of names. It is usually prepared from quinoline-8-sulfonic acid and from a Skraup synthesis from 2-aminophenol [1]. 1-azanapthalene-8-ol is a monoprotic bidentate chelating agent. Related ligands are the Schiff bases derived from salicylaldehyde such as salicylaldoxine, salen, and salicyaldehyde isonicotinoylhydrazene (SIH). The complexes as well as the heterocyclic itself exhibit antiseptic, disinfectant and pesticide properties [2,3], functioning as a transcription inhibitor. Its solution in alcohol is used as liquid bandages. It once was of interest as an anticancer drug, an antiseptic with mild fungistatic, bacteriostatic, anthelmintic, and amebicidal action. It is also used as a reagent and metal chelator, as a carrier for radio-indium for diagnostic purposes, and its halogenated derivatives are used in addition as topical anti-infective agents and oral antiamebics. The reaction of 1-azanapthalene-8-ol with aluminum(III) [4] results in Alq3, a common component of organic light emitting diodes (OLEDs). 1-azanapthalene-8-ol and its derivatives are widely used as chelating reagents in analytical chemistry and radiochemistry from metal ion extraction and fluorometric determination [5]. 1-azanapthalene-8-ol are well known because can perform as structurally related subunits in important bimolecular and biochemical process, which shows strong cytotoxic and antimicrobial properties and they represent the main component in some bactericide, fungicide and antimalarial drugs [6, 7].

*corresponding author; e-mail: sambathk@svce.ac.in
Experimentally it was found that 1-azanapthalene-8-ol has analogous properties such as an intense fluorescence in concentrated acids, lack of fluorescence in water or alkenes or formation of the hydrogen bonded clusters with water, ammonium, or alcohol molecules.

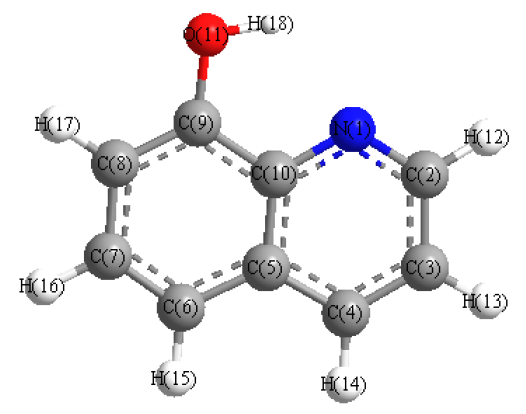

Fig. 1. The geometric structure of 1-azanapthalene$-8-$ ol.

\section{Computational methods}

All calculations were carried out with the Gaussian 03 package [8]. The calculations of systems containing C, $\mathrm{H}, \mathrm{N}$, and $\mathrm{O}$ are described by the standard $6-31 \mathrm{G}(\mathrm{d}, \mathrm{p})$ basis set function of the density functional theory (DFT) $[9,10]$. Geometry optimization was performed utilizing Becker's hybrid three-parameter exchange functional and the nonlocal correlation functional of Lee, Yang, and Parr (B3LYP) [11]. Vibrational analysis was performed at each stationary point found, that confirm its identity as an energy minimum. The population analysis has also been performed by the natural bond orbital method [12] at B3LYP $/ 6-31 \mathrm{G}(\mathrm{d}, \mathrm{p})$ level of theory using natural bond orbital (NBO) program [13] under Gaussian 03 program package.

NBO analysis stresses the role of intermolecular orbital interaction in the complex, particularly charge transfer. This is carried out by considering all possible interactions between filled donor and empty acceptor NBOs and estimating their energetic importance by second-order per- 
turbation theory. For each donor NBO $(i)$ and acceptor NBO $(j)$, the stabilization energy $E^{(2)}$ associated with electron delocalization between donor and acceptor is estimated as

$$
E^{(2)}=q_{i} \frac{\left(F_{i, j}\right)^{2}}{\varepsilon_{j}-\varepsilon_{i}},
$$

where $q_{i}$ is the orbital occupancy, $\varepsilon_{i}, \varepsilon_{j}$ are diagonal elements and $F_{i, j}$ is the off-diagonal NBO Fock matrix element.

\section{Results and discussion}

\subsection{Mulliken atomic charges}

Mulliken atomic charges calculation has an important role in the application of quantum chemical calculation to molecular system because atomic charges affect dipole moment, molecular polarizability, electronic structure, and a lot of properties of molecular systems [14]. The charge distribution over the atoms suggests the formation of donor and acceptor pairs involving the charge transfer in the molecule. Atomic charge has been used to describe the processes of electronegativity equalization and charge transfer in chemical reactions $[15,16]$.

TABLE I

Mulliken atomic charges calculated by B3LYP/ 6-31G(d,p) (BLA) and B3LYP/cc-pVDZ (BLB) methods.

\begin{tabular}{c|r|r|r|r|r}
\hline \hline Atom & BLA & BLB & Atom & BLA & BLB \\
\hline N1 & -0.5093 & -0.1535 & C10 & 0.2566 & 0.1038 \\
C2 & 0.0788 & 0.0576 & O11 & -0.5889 & -0.1829 \\
C3 & -0.1245 & -0.0056 & H12 & 0.0976 & -0.0147 \\
C4 & -0.0849 & 0.0789 & H13 & 0.0966 & -0.0170 \\
C5 & 0.1559 & 0.0739 & H14 & 0.1145 & -0.0106 \\
C6 & -0.1565 & -0.0199 & H15 & 0.0681 & -0.0640 \\
C7 & -0.0990 & 0.0546 & H16 & 0.0862 & -0.0285 \\
C8 & -0.1432 & 0.0348 & H17 & 0.0908 & -0.0305 \\
C9 & 0.3337 & -0.0198 & H18 & 0.3275 & 0.1434
\end{tabular}

The Mulliken atomic charges calculated by methods B3LYP /6-31G(d,p) and B3LYP/cc-pVDZ methods are collected in Table I. It is worthy to mention that $\mathrm{C} 2$, $\mathrm{C} 5$, and $\mathrm{C} 10$ atoms of the title molecule exhibit positive charge while $\mathrm{C} 3, \mathrm{C} 4, \mathrm{C} 6, \mathrm{C} 7, \mathrm{C} 8, \mathrm{C} 9$ atoms exhibit negative charges. Oxygen has a maximum negative charge value of about -0.5888 in the $\mathrm{OH}$ group. The maximum positive atomic is obtained for $\mathrm{C} 10$ which is a carbon present in the $\mathrm{CN}$ functional group. The charge on $\mathrm{H} 18$ in the functional group has the maximum magnitude of 0.3275 among the hydrogen atoms present in the molecule at 6-31G(d,p) and cc-pVDZ level of theory. However all the hydrogen atoms exhibit a net positive charge in $6-31 \mathrm{G}(\mathrm{d}, \mathrm{p})$ basis set while all hydrogen atoms possess negative charge in cc-pVDZ basis set. The presence of large negative charge on $\mathrm{O}$ and $\mathrm{N}$ atom and net positive charge on $\mathrm{H}$ atom may suggest the formation of intermolecular interaction in solid forms [17].

\subsection{NBO analysis}

NBO analysis provides an efficient method for studying intra and intermolecular bonding and interaction among bonds, and also provides a convenient basis for investigation of charge transfer or conjugative interactions in molecular system [18]. Some electron donor orbital, acceptor orbital and the interacting stabilization energy resulting from the second order micro-disturbance theory are reported $[19,20]$. The larger the $E^{(2)}$ value, the more intensive is the interaction between electron donors and the greater the extent of conjugation of the whole system. Delocalization of electron density between occupied Lewis type (bond or lone pair) NBO orbitals and formally unoccupied (antibonding or Rydberg) non Lewis NBO orbital's correspond to a stabling donor-acceptor interaction. NBO analysis was performed on the molecule at the DFT/B3LYP/6-31G(d,p) level in order to elucidate the intra molecular rehybridization and delocalization of electron density within the molecule. The molecular interaction is formed by the orbital overlap between $\sigma(\mathrm{C}-\mathrm{C})$ and $\sigma^{*}(\mathrm{C}-\mathrm{C})$ bond orbital which results that intramolecular charge (ICT) is causing stabilization of the system. These interactions are observed as increase in electron density (ED) in $\mathrm{C}-\mathrm{C}$ antibonding orbital that weakens the respective bonds [21]. The electron density of conjugated double as well as the single bond of the conjugated ring $(\approx 1.9 e)$ clearly demonstrates strong delocalization inside the molecule.

TABLE II

Occupancy of natural orbitals (NBOs) and hybrids of 1-azanaphthalane-8-ol calculated by B3LYP method with $6-31 \mathrm{G}(\mathrm{d}, \mathrm{p})$ basis set for $\mathrm{C}, \mathrm{H}, \mathrm{N}, \mathrm{O}$ atoms.

\begin{tabular}{c|c|c|c}
\hline \hline $\begin{array}{c}\text { Donor } \\
\text { Lewis-type } \\
\text { NBOs }\end{array}$ & Occupancy & Hybrid & AO [\%] \\
\hline$\sigma \mathrm{N} 1-\mathrm{C} 2$ & 1.9828 & $s p^{1.64}$ & $s(37.80 \%) p(60.99 \%) d(0.22 \%)$ \\
$\sigma \mathrm{N} 1-\mathrm{C} 10$ & 1.9744 & $s p^{1.57}$ & $s(38.81 \%) p(60.99 \%) d(0.20 \%)$ \\
$\sigma \mathrm{C} 2-\mathrm{C} 3$ & 1.9751 & $s p^{1.65}$ & $s(37.65 \%) p(62.29 \%) d(0.05 \%)$ \\
$\sigma \mathrm{C} 9-\mathrm{O} 11$ & 1.9922 & $s p^{3.12}$ & $s(24.21 \%) p(75.60 \%) d(0.18 \%)$ \\
$\sigma \mathrm{O} 11-\mathrm{H} 18$ & 1.9909 & $s p^{3.02}$ & $s(24.89 \%) p(75.06 \%) d(0.05 \%)$ \\
$\mathrm{LP}(1) \mathrm{N} 1$ & 1.8923 & $s p^{3.35}$ & $s(22.93 \%) p(76.88 \%) d(0.19 \%)$ \\
$\mathrm{LP}(1) \mathrm{O} 11$ & 1.9771 & $s p^{1.67}$ & $s(37.44 \%) p(62.50 \%) d(0.06 \%)$ \\
$\sigma * \mathrm{~N} 1-\mathrm{C} 2$ & 0.0160 & $s p^{1.64}$ & $s(37.80 \%) p(61.98 \%) d(0.22 \%)$ \\
$\sigma * \mathrm{C} 2-\mathrm{C} 3$ & 0.0310 & $s p^{1.65}$ & $s(37.65 \%) p(62.29 \%) d(0.05 \%)$ \\
$\sigma * \mathrm{C} 2-\mathrm{H} 12$ & 0.0309 & $s p^{2.33}$ & $s(30.02 \%) p(69.95 \%) d(0.03 \%)$ \\
$\sigma * \mathrm{C} 9-\mathrm{O} 11$ & 0.0252 & $s p^{3.12}$ & $s(24.21 \%) p(75.60 \%) d(0.18 \%)$ \\
$\sigma * \mathrm{O} 11-\mathrm{H} 18$ & 0.0146 & $s p^{3.02}$ & $s(24.89 \%) p(75.06 \%) d(0.05 \%)$
\end{tabular}

Table II lists the calculated occupancies of natural orbital's. Three classes of NBOs are included, the Lewis-type ( $\sigma$ and $\pi$ bonding or lone pair) orbital's, the valence non-Lewis (acceptors formally unfilled) orbital's and the Rydberg NBOs, which originate from orbitals outside the atomic valence shell. The calculated natural hybrids on atoms are also given in Table II. As seen from Table II, the $\sigma(\mathrm{N} 1-\mathrm{C} 10)$ bond is formed from $s p^{1.57}$ hybrid on nitrogen (which is the mixture of $38.81 \% s, 60.99 \% p$, and $0.20 \% d$ atomic orbital's). On the other hand, $\sigma(\mathrm{N} 1-\mathrm{C} 2)$ bond is formed from a $s p^{1.64}$ hybrid on nitrogen (which is the mixture of $37.80 \% s, 61.98 \% p$, and $0.22 \% d$ orbitals $)$. The $\pi(\mathrm{C} 9-\mathrm{O} 11)$ is formed from $s p^{3.12}$ hybrid on oxygen (which is the mixture of $24.21 \% s, 75.60 \% p$, and $0.18 \% d)$. 
TABLE III

Second order perturbation theory analysis of the Fock matrix in NBO basis in 1-azanapthalene-8-ol.

\begin{tabular}{|c|c|c|c|c|c|c|c|c|}
\hline Donor $(i)$ & Type & $\operatorname{ED}(e)$ & $\operatorname{Acceptor}(j)$ & Type & $\operatorname{ED}(e)$ & $\begin{array}{c}E^{(2) a} \\
{[\mathrm{~kJ} / \mathrm{mol}]}\end{array}$ & $\begin{array}{c}E(j)-E(i)^{b} \\
\text { [a.u.] }\end{array}$ & $\begin{array}{c}F(i, j)^{c} \\
\text { [a.u.] }\end{array}$ \\
\hline \multirow[t]{3}{*}{$\mathrm{N} 1-\mathrm{C} 2$} & $\sigma$ & 1.98281 & $\mathrm{~N} 1-\mathrm{C} 10$ & $\sigma *$ & 0.02616 & 3.02 & 1.56 & 0.061 \\
\hline & & & $\mathrm{C} 2-\mathrm{C} 3$ & $\sigma *$ & 0.03097 & 1.99 & 1.51 & 0.049 \\
\hline & & & $\mathrm{C} 9-\mathrm{C} 10$ & $\sigma *$ & 0.03088 & 5.17 & 1.54 & 0.080 \\
\hline \multirow[t]{2}{*}{ N1-C2 } & $\pi$ & 1.82390 & $\mathrm{C} 3-\mathrm{C} 4$ & $\pi *$ & 0.19090 & 8.50 & 0.39 & 0.052 \\
\hline & & & $\mathrm{C} 5-\mathrm{C} 10$ & $\sigma *$ & 0.05370 & 0.52 & 0.99 & 0.021 \\
\hline \multirow[t]{2}{*}{ N1-C10 } & $\sigma$ & 1.97443 & $\mathrm{~N} 1-\mathrm{C} 2$ & $\sigma *$ & 0.01605 & 2.85 & 1.54 & 0.059 \\
\hline & & & $\mathrm{C} 5-\mathrm{C} 10$ & $\sigma *$ & 0.05370 & 4.45 & 1.55 & 0.075 \\
\hline \multirow[t]{2}{*}{$\mathrm{C} 2-\mathrm{C} 3$} & $\sigma$ & 1.97506 & $\mathrm{~N} 1-\mathrm{C} 2$ & $\sigma *$ & 0.01605 & 2.20 & 1.40 & 0.050 \\
\hline & & & $\mathrm{C} 4-\mathrm{C} 14$ & $\sigma *$ & 0.02375 & 5.29 & 1.16 & 0.070 \\
\hline \multirow[t]{2}{*}{ C2-H12 } & $\sigma$ & 1.97053 & $\mathrm{~N} 1-\mathrm{C} 10$ & $\sigma *$ & 0.02616 & 5.01 & 1.21 & 0.070 \\
\hline & & & $\mathrm{C} 3-\mathrm{C} 4$ & $\pi *$ & 0.19090 & 3.82 & 0.59 & 0.044 \\
\hline $\mathrm{C} 3-\mathrm{C} 4$ & $\sigma$ & 1.96835 & $\mathrm{C} 2-\mathrm{C} 3$ & $\sigma *$ & 0.03097 & 4.48 & 1.44 & 0.072 \\
\hline \multirow[t]{2}{*}{$\mathrm{C} 3-\mathrm{C} 4$} & $\pi$ & 1.69240 & $\mathrm{~N} 1-\mathrm{C} 2$ & $\pi *$ & 0.1605 & 28.18 & 0.33 & 0.086 \\
\hline & & & $\mathrm{C} 2-\mathrm{H} 2$ & $\sigma *$ & & 0.57 & 0.73 & 0.020 \\
\hline C3-H13 & $\sigma$ & 1.97102 & $\mathrm{C} 4-\mathrm{C} 5$ & $\sigma *$ & 0.03127 & 4.13 & 1.16 & 0.062 \\
\hline $\mathrm{C} 4-\mathrm{C} 5$ & $\sigma$ & 1.95722 & C3-H13 & $\sigma *$ & 0.02555 & 7.02 & 1.14 & 0.080 \\
\hline C4-H14 & $\sigma$ & 1.96774 & $\mathrm{C} 5-\mathrm{C} 10$ & $\sigma *$ & 0.05370 & 4.83 & 1.20 & 0.068 \\
\hline $\mathrm{C} 5-\mathrm{C} 6$ & $\sigma$ & 1.95703 & $\mathrm{C} 6-\mathrm{C} 7$ & $\sigma *$ & 0.01691 & 4.07 & 1.39 & 0.068 \\
\hline $\mathrm{C} 6-\mathrm{C} 7$ & $\pi$ & 1.97566 & $\mathrm{C} 8-\mathrm{C} 9$ & $\pi *$ & 0.33166 & 14.11 & 0.32 & 0.061 \\
\hline $\mathrm{C} 8-\mathrm{C} 9$ & $\pi$ & 1.97178 & $\mathrm{C} 6-\mathrm{C} 7$ & $\pi *$ & 0.29364 & 19.68 & 0.31 & 0.070 \\
\hline \multirow[t]{3}{*}{ C10 } & $\mathrm{LP}(1)$ & 1.0388 & $\mathrm{C} 2-\mathrm{C} 3$ & $\sigma *$ & 0.03097 & 10.44 & 0.97 & 0.091 \\
\hline & & & $\mathrm{N} 1-\mathrm{C} 2$ & $\pi *$ & 0.32514 & 81.91 & 0.13 & 0.113 \\
\hline & & & $\mathrm{C} 8-\mathrm{C} 9$ & $\pi *$ & 0.33166 & 83.18 & 0.16 & 0.123 \\
\hline O11 & $\operatorname{LP}(2)$ & 1.86739 & $\mathrm{C} 8-\mathrm{C} 9$ & $\pi *$ & 0.33166 & 30.01 & 0.36 & 0.098 \\
\hline
\end{tabular}

In Table III the perturbation energies of donoracceptor interactions are presented. In our title molecule 1-azanapthalene-8-ol $\pi(\mathrm{C} 3-\mathrm{C} 4) \rightarrow \pi^{*}(\mathrm{~N} 1-\mathrm{C} 2)$ has $28.18 \mathrm{~kJ} / \mathrm{mol}, \pi(\mathrm{C} 8-\mathrm{C} 9) \rightarrow \pi^{*}(\mathrm{C} 6-\mathrm{C} 7)$ has $19.68 \mathrm{~kJ} / \mathrm{mol}$ and $\pi(\mathrm{C} 6-\mathrm{C} 7) \rightarrow \pi^{*}(\mathrm{C} 8-\mathrm{C} 9)$ has $14.11 \mathrm{~kJ} / \mathrm{mol}$ and hence they give stronger stabilization to the structure. From Table II it is noted that the maximum occupancies $1.98282,1.97443,1.97506,1.97556$ are obtained for $\sigma(\mathrm{N} 1-\mathrm{C} 2), \sigma(\mathrm{N} 1-\mathrm{C} 10), \sigma(\mathrm{C} 2-\mathrm{C} 3)$, and $\pi(\mathrm{C} 6-\mathrm{C} 7)$, respectively. Therefore the results suggest that the $\sigma(\mathrm{N} 1-\mathrm{C} 2), \sigma(\mathrm{N} 1-\mathrm{C} 10), \sigma(\mathrm{C} 2-\mathrm{C} 3)$, and $\pi(\mathrm{C} 6-\mathrm{C} 7)$ are essentially controlled by the $p$-character of the hybrid orbital's.

The same kind of interaction is calculated in the same kind of interaction energy, related to the resonance in the molecule, is electron donating from $\mathrm{LP}(1) \mathrm{C} 10$ to $\sigma^{*}(\mathrm{C} 2-\mathrm{C} 3)$, shows less stabilization of $10.44 \mathrm{~kJ} / \mathrm{mol}$ and further $\mathrm{LP}(1) \mathrm{C} 10$ to $\pi^{*}(\mathrm{~N} 1-\mathrm{C} 2)$, leads to strong stabilization energy of $81.91 \mathrm{~kJ} / \mathrm{mol}$ and $\mathrm{LP}(1) \mathrm{C} 10$ to $\pi^{*}(\mathrm{C} 8-\mathrm{C} 9)$ resulting in an enormous stabilization of $83.18 \mathrm{~kJ} / \mathrm{mol}$. The strong intra-molecular hyper conjugation interaction of the $\sigma$ and the $\pi$ electrons of $\mathrm{C}-\mathrm{C}$ to the anti $\mathrm{C}-\mathrm{C}$ bond in the ring leads to stabilization of some part of the ring as evident from Table III.

\subsection{Fukui functions}

DFT is one of the important tools of quantum chemistry to understand popular chemical concepts such as electronegativity, electron affinity, chemical potential, and ionization potential. In order to solve the negative Fukui function problem, different attempts have been made by various groups [22]. Kolandaivel et al. [23] introduced the atomic descriptor to determine the local reactive sites of the molecular system. In the present study, the optimized molecular geometry was utilized in single-point energy calculations, which have been performed at the DFT for the anions and cations of the title compound using the ground state with doublet multiplicity. The individual atomic charges calculated by natural population analysis (NPA) and Mulliken population analysis (MPA) have been used to calculate the Fukui function.

Table IV shows the $f_{k}^{+}, f_{k}^{-}$and $f_{k}^{0}$ values for the title molecule calculated by NPA and MPA gross charges at DFT level of theory with the basis set (B3LYP/ 6-31G(d,p)). It has been found that both NPA and MPA scheme methods predict that the nitrogen atom N1 has a higher $f_{k}^{+}$value for nucleophilic attack. Also both the 
TABLE IV

TABLE V

Condensed Fukui functions calculated by B3LYP/ $6-31 G(d, p)$ from the NPA and MPA schemes.

\begin{tabular}{l|c|c|c|c|c|c}
\hline \hline Atoms & \multicolumn{3}{|c|}{ MPA } & \multicolumn{3}{c}{ NPA } \\
\cline { 2 - 7 } & $f_{k}^{+}$ & $f_{k}^{-}$ & $f_{k}^{0}$ & $f_{k}^{+}$ & $f_{k}^{-}$ & $f_{k}^{0}$ \\
\hline N1 & 0.4701 & -0.3344 & 0.0679 & 0.0852 & 0.1005 & 0.0929 \\
C2 & -0.1407 & -0.5256 & -0.3332 & 0.0626 & -0.0167 & 0.0230 \\
C3 & 0.0174 & 0.1277 & 0.0726 & 0.1093 & 0.0964 & 0.1029 \\
C4 & 0.0147 & 0.6649 & 0.3398 & 0.0804 & 0.1471 & 0.1138 \\
C5 & 1.1193 & -2.5394 & -0.7101 & -0.0194 & -0.0190 & -0.0192 \\
C6 & -0.1619 & -0.0423 & -0.1021 & 0.2147 & -0.0137 & 0.1005 \\
C7 & -0.1780 & -0.0936 & -0.1358 & 0.0552 & 0.0043 & 0.0298 \\
C8 & 0.3466 & -0.1646 & 0.0910 & 0.1439 & 0.0204 & 0.0822 \\
C9 & -0.8558 & 0.8845 & 0.0144 & 0.0872 & 0.0322 & 0.0597 \\
C10 & -1.0076 & 2.0707 & 0.5316 & -0.0185 & 0.0315 & 0.0065 \\
O11 & 0.4396 & -0.2676 & 0.0860 & 0.1400 & 0.0104 & 0.0752 \\
H12 & 0.1636 & 0.6069 & 0.3853 & 0.0032 & 0.1731 & 0.0882 \\
H13 & 0.1403 & 0.3654 & 0.2529 & 0.0127 & 0.1262 & 0.0695 \\
H14 & 0.1416 & 0.1849 & 0.1633 & 0.0108 & 0.0942 & 0.0525 \\
H15 & 0.1586 & -0.0032 & 0.0777 & 0.0059 & 0.0568 & 0.0314 \\
H16 & 0.1535 & 0.0014 & 0.0775 & 0.0079 & 0.0636 & 0.0358 \\
H17 & 0.1780 & -0.0214 & 0.0783 & 0.0110 & 0.0600 & 0.0355 \\
H18 & 0.0004 & 0.0857 & 0.0431 & 0.0076 & 0.0327 & 0.0202
\end{tabular}

population analysis schemes show N1 nitrogen atom as the reactive sites for receiving a nucleophilic. From the values reported in Table IV the reactivity order for the electrophilic case was C9 > C4 > C3 for MPA analysis. On the other hand, for nucleophilic attack both N1 and O11 have greater reactivity value. The attack for radical case was $\mathrm{C} 10>\mathrm{C} 4$ for MPA. If one compares the three kinds of attacks, it is possible to observe that the electrophilic attack has bigger reactivity compared to the nucleophilic and radial attack.

\subsection{First order hyperpolarizability calculations}

Polarizabilities and hyperpolarizabilities characterize the response of a system in an applied electric field [24]. They determine not only the strength of molecular interactions as well as the cross-sections of different scattering and collision processes, but also the non-linear optical (NLO) properties of the system [25, 26]. In order to investigate the relationships among photocurrent generation, molecular structures and NLO, the polarizabilities and hyperpolarizabilities of title compound was calculated using B3LYP method, 6-31G(d,p) basis set, based on the finite-field approach. The first order hyperpolarizability $(\beta)$ of title molecule along with related properties $\left(\mu, \alpha\right.$, and $\left.\alpha_{0}\right)$ are reported in Table V. The calculated value of dipole moment was found to be $1.03354 \mathrm{D}$ at B3LYP/6-31G(d,p). In addition to the isotropic polarizabilities and polarizabilities anisotropy invariants were also calculated. The calculated anisotropy of the polarizability $\alpha_{0}$ of 1 -azanapthalene- $8-o l$ is 249.8787 a.u. at B3LYP/6-31G(d,p) level. The magnitude of the molecular hyperpolarizability $\beta$ is one of key factors in a NLO system. The B3LYP/6-31G(d,p) calculated first order hyperpolarizability value $\left(\beta_{0}\right)$ of 1 -azanapthalene- 8 -ol is equal to $2.4302 \times 10^{-30}$ esu. Total dipole moment of title molecule is slightly smaller than those of urea and
The B3LYP/6-31G(d,p) calculated electric dipole moments (Debye), polarizability (in a.u.), B components and $\beta_{\text {tot }}$ $\left(10^{-31} \mathrm{esu}\right)$ value of 1-azanapthalene-8-ol.

\begin{tabular}{c|c|c|c}
\hline \hline Parameters & $\begin{array}{c}\text { B3LYP/ } \\
6-31 \mathrm{G}(\mathrm{d}, \mathrm{p})\end{array}$ & Parameters & $\begin{array}{c}\mathrm{B} 3 \mathrm{LYP} / \\
6-31 \mathrm{G}(\mathrm{d}, \mathrm{p})\end{array}$ \\
\hline$\mu_{x}$ & 0.70363 & $\beta_{x x x}$ & 153.85928 \\
$\mu_{y}$ & -0.74025 & $\beta_{x x y}$ & 0.715038 \\
$\mu_{z}$ & -0.15871 & $\beta_{x y y}$ & 16.87299 \\
$\mu$ & 1.03354 & $\beta_{y y y}$ & -186.3781 \\
$\alpha_{x x}$ & 136.04879 & $\beta_{x x z}$ & -33.5478 \\
$\alpha_{x y}$ & 0.126794 & $\beta_{x y z}$ & 26.81478 \\
$\alpha_{y y}$ & 104.51901 & $\beta_{y y z}$ & 25.29785 \\
$\alpha_{x z}$ & -3.49817 & $\beta_{x z z}$ & 18.6219 \\
$\alpha_{y z}$ & -2.60709 & $\beta_{y z z}$ & -20.5898 \\
$\alpha_{z z}$ & 41.75965 & $\beta_{z z z}$ & -18.7576 \\
$\alpha_{0}$ & 94.1091 & $\beta_{\text {tot }}(\mathrm{esu})$ & $2.4302 \times 10^{-30}$ \\
$\alpha$ & 249.8787 & &
\end{tabular}

first order hyperpolarizability of title molecule is approximately eight times greater than those of urea. This result indicates the nonlinearity of the title molecule.

\section{Conclusion}

According to our results the following conclusions are derived for the 1-azanapthalene-8-ol.

1. The NBO analysis has provided the detailed insight into the type of hybridization and the nature of bonding in 1-azanapthalene-8-ol. The $\sigma(\mathrm{N} 1-\mathrm{C} 2)$ bonds are formed from $s p^{1.64}$ hybrid on nitrogen atom and $\pi(\mathrm{C} 9-\mathrm{O} 11)$ bond is formed from $s p^{3.12}$. The strongest electron donation occurs from a lone pair to the anti-bonding acceptor $\pi^{*}(\mathrm{C} 8-\mathrm{C} 9)$ orbital's.

2. The predicted first order hyperpolarizability shows that the molecule might have a reasonably good NLO behavior. Mulliken atomic charges analysis shows that charge transfer occurs within the molecule. NBO results reflect the charge transfer mainly due to $\mathrm{C}-\mathrm{O}$ group.

\section{References}

[1] G. Collin, H. Höke, Ullmann's Encyclopedia of Industrial Chemistry, Wiley-VCH, Weinheim 2005.

[2] J.P. Phillips, Chem. Rev. 56, 27 (1956).

[3] "8-Hydroxyquinoline", Medical Dictionary Online, 2002.

[4] R. Katakura, Y. Koide, Inorg. Chem. 45, 5730 (2006).

[5] K.G. Stone, L. Friedman, J. Am. Chem. Soc. 69, 209 (1947).

[6] M. Santo, R. Cattana, J.J. Silber, Spectrochim. Acta A 57, 1541 (2001).

[7] C. Reichardt, Solvents and Solvent Effects in Organic Chemistry, 3rd ed., Wiley-VCH Verlag Weinheim 2003. 
[8] M.J. Frisch, G.W. Trucks, H.B. Schlegel, G.E. Suzerain, M.A. Robb, J.R. Cheeseman Jr., J.A. Montgomery, T. Vreven, K.N. Kudin, J.C. Burant, J.M. Millam, S.S. Iyengar, J. Tomasi, V. Barone, B. Mennucci, M. Cossi, G. Scalmani, N. Rega, G.A. Petersson, H. Nakatsuji, M. Hada, M. Ehara, K. Toyota, R. Fukuda, J. Hasegawa, M. Ishida, T. Nakajima, Y. Honda, O. Kitao, H. Nakai, M. Klene, X. Li, J.E. Knox, H.P. Hratchian, J.B. Cross, V. Bakken, C. Adamo, J. Jaramillo, R. Gomperts, R.E. Stratmann, O. Yazyev, A.J. Austin, R. Cammi, C. Pomelli, J.W. Ochterski, P.Y. Ayala, K. Morokuma, G.A. Voth, P. Salvador, J.J. Dannenberg, V.G. Zakrzewski, S. Dapprich, A.D. Daniels, M.C. Strain, O. Farkas, D.K. Malick, A.D. Rabuck, K. Raghavachari, J.B. Foresman, J.V. Ortiz, Q. Cui, A.G. Baboul, S. Clifford, J. Cioslowski, B. Stefanov, G. Liu, A. Liashenko, P. Piskorz, I. Komaromi, R.L. Martin, D.J. Fox, T. Keith, M.A. Al-Laham, C.Y. Peng, A. Nanayakkara, M. Challacombe, P.M.W. Gill, B. Johnson, W. Chen, M.W. Wong, C. Gonzalez, J.A. Pople, Gaussian 03, Revision A.I, Gaussian, Inc, Pittsburgh (PA) 2003.

[9] P.C.HAriharan, J.A. Pople, Theor. Chim. Acta 28, 213 (1973).

[10] P.C. Hariharan, J.A. Pople, Mol. Phys. 27, 209 (1974).

[11] A.D. Becke, J. Chem. Phys. 98, 5648 (1993).

[12] A.E. Reed, L.A. Curtiss, F. Weinhold, Chem. Rev. 88, 899 (1988).

[13] E.D. Glendening, A.E. Reed, J.E. Carpenter, F. Weinhold, J. Am. Chem. Soc. 120, 12051 (1998).
[14] I. Sidir, Y.G. Sidir, M. Kumalar, E. Tasal, J. Mol. Struct. 134, 964 (2010).

[15] K. Jug, Z.B. Maksic, in: Theoretical Model of Chemical Bonding, Ed. Z.B. Maksic, Part 3, Springer, Berlin 1991, p. 29, p. 233.

[16] S. Fliszar, Charge Distributions and Chemical Effects, Springer, New York 1983.

[17] L.X. Hong, L.X. Ru, Z.X. Zhou, Comput. Theor. Chem. 969, 27 (2011).

[18] M. Snehalatha, C. Ravikumar, I. Hubert Joe, N. Sekar, V.S. Jayakumar, Spectrochim. Acta $\mathbf{7 2 A}$, 654 (2009).

[19] C. James, A. Amal Raj, R. Reghunathan, I.H. Joe, V.S. Jayakumar, J. Raman Spectrosc. 37, 138 (2006).

[20] J. Liu, Z. Chen, S. Yuan, J. Zhejiang, Univ. Sci. B 6, 584 (2005).

[21] S. Sebastin, N. Sundaraganesan, Spectrochim. Acta A 75, 941 (2010).

[22] P. Kolandaivel, G. Praveen, P. Selvarengan, J. Chem. Sci. 117, 591 (2005).

[23] R.K. Roy, K. Hirao, S. Krishnamurthy, S. Pal, J. Chem. Phys. 115, 2901 (2001).

[24] C.R. Zhang, H.S. Chen, G.H. Wang, Chem. Res. Chin. U 20, 640 (2004).

[25] Y. Sun, X. Chen, L. Sun, X. Guo, W. Lu, Chem. Phys. Lett. 38, 397 (2003).

[26] O. Christiansen, J. Gauss, J.F. Stanton, Chem. Phys. Lett. 305, 147 (1999). 